\title{
Role of Quantitative Diffusion-Weighted Imaging in Differentiating Benign and Malignant Orbital Masses
}

\author{
${ }^{1}$ Department of Radio-Diagnosis, Advanced Imaging Point, Nagpur, \\ Maharashtra, India \\ 2Department of Radio-Diagnosis, Manipal Hospital, Bangalore, \\ Karnataka, India \\ ${ }^{3}$ Department of Neuroimaging and Interventional Radiology, \\ Manipal Hospital, Bangalore, Karnataka, India \\ ${ }^{4}$ Department of Bioanalytics, MDS Bioanalytics, Nagpur, \\ Maharashtra, India
}

Preeti Mundhada ${ }^{1}$ Sudarshan Rawat ${ }^{2} \quad$ Ullas Acharya $^{3} \quad$ Dhananjay Raje $^{4}$

\begin{abstract}
Address for correspondence Preeti Mundhada, DMRD, DNB RadioDiagnosis, Department of Radio-Diagnosis, Advanced Imaging Point, Nikalas Tower, Central Bazar Road, Ramdaspeth, Nagpur 440010, Maharashtra, India

(e-mail: preetimundhada21@gmail.com).
\end{abstract}

Indian J Radiol Imaging 2021;31:102-108.

\begin{abstract}
Keywords

- ADC value

- benign

- diffusion-weighted imaging

- malignant

- orbital mass

Aim To determine the role of diffusion-weighted imaging (DWI) with apparent diffusion coefficient (ADC) values in differentiating benign and malignant orbital masses. Materials and Methods After obtaining institutional ethical board approval and informed consent from all patients, an observational study was done for a period of 24 months in the radiology department of a tertiary care hospital in South India. Conventional magnetic resonance imaging and DWI using a 3 T scanner was done for all patients with suspected orbital mass lesion. ADC value and clinicohistopathological correlation were studied for every patient. Chi-square test was used to compare the signal characteristics of DWI and ADC maps between benign and malignant lesions. A comparison of mean ADC values for benign and malignant masses was performed using Student's $t$-test for independent samples. The cut-off value for ADC was obtained using the receiver operating characteristic (ROC) curve.

Results Of 44 patients with orbital lesions, $70 \%$ were benign and $30 \%$ were malignant. There was a significant difference in the mean ADC values of benign and malignant orbital masses. Using ROC curve analysis, an optimal ADC threshold of $1.26 \times 10^{-3} \mathrm{~mm}^{2} / \mathrm{s}$ was calculated for the prediction of malignancy with $100 \%$ sensitivity, $80.65 \%$ specificity, and $86.36 \%$ accuracy (95\% confidence interval: $0.872,1.00, p<0.0001)$. Two ADC thresholds were used to characterize the orbital masses with more than $90 \%$ confidence. Conclusion Quantitative assessment of $A D C$ is a useful noninvasive diagnostic tool for differentiating benign and malignant orbital masses. Malignant orbital lesions demonstrate significantly lower ADC values as compared with benign lesions.
\end{abstract}

\section{Introduction}

The orbit is a small anatomical space containing various important structures. ${ }^{1}$ Orbital pathologies assume critical importance as the eyeball forms the most important sense

published online May 23, 2021
Dol https://doi.org/

$10.1055 / \mathrm{s}-0041-1730120$

ISSN 0971-3026 organ in humans. The conditions that affect vision have a great impact on several aspects of an individual's life. Various pathologies affecting the orbit can be broadly categorized as congenital, vascular, infectious/inflammatory, and neoplastic (includes both benign and malignant lesions). ${ }^{2}$ (c) 2021. Indian Radiological Association

This is an open access article published by Thieme under the terms of the Creative Commons Attribution-NonDerivative-NonCommercial-License, permitting copying and reproduction so long as the original work is given appropriate credit. Contents may not be used for commercial purposes, or adapted, remixed, transformed or built upon. (https://creativecommons.org/licenses/by-nc-nd/4.0/).

Thieme Medical and Scientific Publishers Private Ltd. A-12, Second Floor, Sector -2, NOIDA -201301, India 
A good understanding of orbital anatomy is crucial for orbital imaging. ${ }^{3,4}$ A compartment-based approach toward the evaluation of orbital masses simplifies the diagnostic approach and helps to narrow down the differential diagnoses. ${ }^{5}$ As there are numerous possible etiologies of orbital masses, arriving at the correct clinical diagnosis can be challenging. Orbital imaging is commonly performed for patients presenting with proptosis, visual impairment, diplopia, leukocoria, eye pain, and trauma. Magnetic resonance imaging (MRI) has superseded other modalities to become the most accurate imaging modality due to superior soft-tissue contrast, better multiplanar examinations, and lack of irradiation. ${ }^{6}$ It provides crucial information regarding the ocular structures involved, the extent of involvement, and intracranial extension. ${ }^{7}$

The role of advanced imaging techniques such as diffusion-weighted imaging (DWI) in the initial staging and posttreatment follow-up of head and neck cancers is being increasingly recognized. DWI is being used to differentiate benign and malignant thyroid nodules, cervical lymph nodes, and parotid masses. ${ }^{8}$ The application of DWI in the orbit is limited as compared with other head and neck cancers due to geometric distortion caused by the adjacent air, bone, and soft tissue interfaces. Newer imaging techniques such as single- and multishot echo-planar DWI are being developed for adequate evaluation of orbital masses and optic nerve pathologies. Parallel imaging techniques are being developed to overcome the limitations of magnetic susceptibility artifacts caused by echo-planar imaging (EPI). ${ }^{1}$

Qualitative assessment of signal intensity on diffusion-weighted images may not reveal significant differences between benign and malignant lesions due to the presence of the T2 shine-through effect in benign lesions. Hence, a quantitative assessment using apparent diffusion coefficient (ADC) maps is required for more accurate characterization of lesions since ADC is only affected by changes in diffusivity. ${ }^{9-11}$

Most of the studies in the literature reported heterogeneity of equipment and scanning techniques, study cohort of specific predominant lesions, comparison of particular orbital masses like pseudotumor versus lymphoma, and interobserver variability. ${ }^{12-14}$ This study was undertaken to eliminate the biases related to the machine, scanning techniques, and interobserver variations. A more heterogeneous group of benign and malignant masses was included in this study for better generalization of results. As earlier studies have reported different ADC cut-off values to differentiate benign and malignant orbital masses, we proposed a two-threshold model for better characterization of orbital lesions.

The present study was aimed to determine the role of DWI with ADC values in differentiating benign and malignant orbital masses.

\section{Materials and Methods}

\section{Patient Population}

An observational study was performed in the radiology department of a tertiary care hospital in South India from April 2017 till April 2019. After institutional ethical board approval, written informed consent was obtained from all the patients. All patients with clinically suspected orbital mass lesions referred to the radiology department for orbital MRI were included. Patients operated for orbital mass lesions and referred for follow-up study, patients with general contraindications for MRI, and those not willing to undergo MRI were excluded. Clinicohistopathological correlations were studied for every patient.

Data acquisition: The patient demographic data were recorded in the case record form. Patients were instructed to remove all metallic belongings before the examination. Pediatric patients and noncooperative patients were sedated to minimize motion artifacts. All the patients were subjected to conventional MRI and DWI. MRI was performed using a 3T (Philips Ingenia) scanner, using a 16-channel head coil with the patient in the supine position. ${ }^{15,16} \mathrm{~A}$ scout sagittal T1-weighted image was obtained to confirm the position of the patient and to act as a localizer for subsequent image acquisitions. ${ }^{17}$ Initially, 3D FLAIR brain screening was performed in all cases. All the patients underwent conventional orbital imaging, including $\mathrm{T} 1$-weighted and T2-weighted imaging with fat suppression. Multiplanar contrast-enhanced T1-weighted fat-suppressed image was obtained in axial, coronal, and sagittal planes after the administration of $0.1 \mathrm{mmol} / \mathrm{kg}$ dose of gadolinium-based intravenous contrast (Magnevist/Multihance/Omniscan). DWI was performed in the axial plane using a single-shot echo-planar imaging sequence with $b$-values of 0 and 1,000 second $\mathrm{mm}^{2}$. The following imaging parameters were used: average TR/TE of 6,500/65 ms for DWI, field of view of 16 to $18 \mathrm{~cm}$, slice thickness of $4 \mathrm{~mm}$, interslice gap of 1 to $2 \mathrm{~mm}$, and a matrix of $256 \times 256$. Additional sequences like gradient and balanced steady-state sequences were used if clinically indicated.

Data analysis: Images were sent to the workstation and the PACS server for analysis. The high-resolution T2-weighted images were assessed first to localize the lesion in each case. An ADC map was generated for every patient. The lesion was identified on the ADC map image using multiplanar cross-reference with the conventional images. The quantitative ADC value was calculated by drawing a freehand region of interest within the lesion on the ADC map. The peripheral aspects of the lesion and areas of necrosis seen on the ADC map were excluded to avoid the effect of partial volume averaging. The areas of calcification were not excluded while calculating the $\mathrm{ADC}$ value.

\section{Statistical Analysis}

The diagnostic parameters of DWI with ADC were obtained in terms of sensitivity, specificity, positive predictive value, and negative predictive value. Chi-square test was used to compare the signal characteristics of the DWI and ADC maps of benign and malignant lesions. The comparison of mean ADC values for benign and malignant masses was performed using Student's $t$-test for independent samples. The cut-off value for ADC was obtained using the receiver operating characteristic (ROC) curves. All the analyses were performed using IBM SPSS Statistics 20 and a $p$-value of less than 0.05 was considered statistically significant. 


\section{Results}

The baseline characteristics of patients with suspected orbital mass lesions included in our study for a period of 24 months are shown in - Table 1. It was observed that patients belonged to all age groups ranging from 1 year to 73 years with a mean age of 32.93 years. We found a female preponderance in our study with 29 (66\%) female patients and 15 (34\%) male patients. There were 31 (70\%) benign orbital lesions and 13 (30\%) malignant lesions.

The final diagnosis was established by histopathological examination in majority of the cases $(n=34)$ or based on the patient's therapeutic response to antibiotics, anti-inflammatory drugs, and use of corticosteroids $(n=10)$. - Table 2 illustrates the correlation between the imaging and clinical/histopathology findings.

- Table 3 demonstrates the diffusion-weighted appearances of different orbital lesions. It shows that the distributions of DWI appearances of benign and malignant lesions were significantly different from each other $(p=0.002)$.

- Table 4 shows the distribution of all the benign and malignant orbital masses encountered in our study along with their mean $A D C$ values. The mean ADC for the benign group was $1.47 \pm 0.28 \times 10^{-3} \mathrm{~mm}^{2} / \mathrm{s}$ and that for the malignant group was $0.94 \pm 0.210^{-3} \mathrm{~mm}^{2} / \mathrm{s}$. The difference between the mean $A D C$ values for the two groups was found to be statistically significant $(p<0.00001)$.

We also assessed the risk of malignancy with respect to the age of the patient, gender, and size of the lesion using the odds ratio as shown in - Table $\mathbf{5}$. We found 23 lesions (52\%) greater than $15 \mathrm{~mm}$ in size.

- Figs. 1 to 4 show the imaging appearances of some of the benign and malignant orbital masses in our study.

ROC curve analysis was performed to calculate the optimal ADC threshold for the diagnosis of malignancy. The area under the curve was measured as 0.938 and the optimal ADC threshold was identified at the point of maximum accuracy. - Fig. 5 shows that $1.26 \times 10^{-3} \mathrm{~mm}^{2} / \mathrm{s}$ was identified as the optimal cut-off value of ADC for characterizing orbital masses with a sensitivity of $100 \%$, a specificity of $80.65 \%$, and an accuracy of $86.36 \%$.

The sensitivity and specificity at different ADC threshold values are shown in - Table 6. It was seen that an ADC threshold of less than $1.04 \times 10^{-3} \mathrm{~mm}^{2} / \mathrm{s}$ was more than $90 \%$ specific for malignancy, and an ADC threshold of less than 1.22 $\times 10^{-3} \mathrm{~mm}^{2} / \mathrm{s}$ was more than $90 \%$ sensitive for malignancy.

Table 1 Demographics and baseline characteristics

\begin{tabular}{|l|l|l|}
\hline Characteristics & Categories & $\begin{array}{l}\text { Descriptive } \\
\text { statistics }\end{array}$ \\
\hline $\begin{array}{l}\text { Age in } \\
\text { years [mean } \pm \text { SD] }\end{array}$ & $32.93 \pm 22.94$ \\
\hline Gender [No. (\%)] & Male & $15(34.09)$ \\
\cline { 2 - 3 } & Female & $29(65.91)$ \\
\hline Tumor type [No. (\%)] & Benign & $31(70.45)$ \\
\cline { 2 - 3 } & Malignant & $13(29.54)$ \\
\hline
\end{tabular}

Abbreviation: SD, standard deviation.
Table 2 Orbital MRI and clinical*/histopathological correlation (C/HPR)

\begin{tabular}{|c|c|c|}
\hline $\mathrm{MRI}_{\mathrm{MR}} \mathrm{C} / \mathrm{HPR}$ & $\begin{array}{c}\text { Benign }(n=31) \\
{[\text { No. }(\%)]}\end{array}$ & $\begin{array}{c}\text { Malignant }(n=13) \\
{[\text { No. }(\%)]}\end{array}$ \\
\hline Benign $(n=27)$ & $26(83.87)$ & $1(7.69)$ \\
\hline Malignant $(n=17)$ & $5(16.12)$ & $12(92.30)$ \\
\hline
\end{tabular}

Abbreviation: MRI, magnetic resonance imaging.

"Final diagnosis based on therapeutic response $(n=10)$.

\section{Discussion}

DWI uses the diffusivity of moving water protons in different tissues to produce image contrast and thus provides useful information for the assessment of pathological tissues. ${ }^{12,18}$ Malignant lesions demonstrate restricted diffusion due to higher cellularity and higher nuclear-cytoplasmic ratio within the cells. There are few studies reported in the literature evaluating the role of quantitative diffusion-weighted images in differentiating benign and malignant orbital masses. Some of the earlier studies have suggested that DWI has a role in the prediction of malignancy in orbital masses, differentiation of orbital lymphoma from pseudotumors, evaluation of orbital cellulitis, identification of orbital abscess, and assessment of optic nerve lesions and infa rct. $817,19-22$

To the best of our knowledge, this is the first study evaluating the role of DWI and ADC values in orbital mass lesions among the Indian population. In our study, a total of 44 patients clinically suspected of having an orbital mass lesion underwent conventional MRI along with DWI with an aim of evaluating the role of DWI and ADC values in differentiating benign and malignant orbital lesions.

In our study, we found that majority of the patients had benign orbital masses (70\%) and only one-third had malignant masses (30\%). Our results were in agreement with the studies reported in the literature by various researchers. Shields et al reported $64 \%$ benign and 36\% malignant lesions in a retrospective study. ${ }^{23}$ Hemat also found $68 \%$ benign orbital lesions while $32 \%$ malignant lesions in his study. ${ }^{17}$ However, Ro et al reported almost equal distribution of benign and malignant orbital lesions in one of their studies. ${ }^{24}$

Histopathological examination was done to attain the final diagnosis in 34 cases. The final diagnosis was established from the clinical course of the disease after medical management in the remaining 10 patients. Imaging and clinical/histopathology findings were in agreement in $84 \%$ benign cases and $92 \%$ malignant cases.

In our study, the majority of the benign lesions were vascular in origin consisting of lymphangioma (5), hemangioma (2), and orbital varix (1). Inflammatory masses included pseudotumor (3), granulomatosis with polyangiitis (2), and a solitary case of Erdheim-Chester disease and immunoglobulin G 4 (IgG4)-related disease each. Benign optic nerve sheath complex lesions composed of six cases of optic nerve glioma and a case of optic nerve sheath meningioma. Orbital infections included a case of endophthalmitis, panophthalmitis, 
Table 3 Distribution of orbital tumors according to appearance on DWI

\begin{tabular}{|c|c|c|c|c|}
\hline Classification of tumor & & DWI [N & & $p$ \\
\hline & Isointense & Hypointense & Hyperintense & \\
\hline Benign $(n=31)$ & $2(6.45)$ & $16(51.61)$ & $13(41.93)$ & $0.002^{\mathrm{a}}$ \\
\hline Malignant $(n=13)$ & $6(46.15)$ & 1 (7.69) & $6(46.15)$ & \\
\hline
\end{tabular}

Abbreviation: DWI, diffusion-weighted imaging.

abtained using Chi-square test.

Table 4 Descriptive statistics for ADC value according to the type of orbital tumor

\begin{tabular}{|l|l|l|l|}
\hline Type of tumor (No.) & Minimum ADC $\left(10^{-3} \mathrm{~mm}^{2} / \mathrm{s}\right)$ & Maximum ADC $\left(10^{-3} \mathrm{~mm}^{2} / \mathrm{s}\right)$ & ADC $\left(10^{-3} \mathrm{~mm}^{2} / \mathrm{s}\right)(\mathrm{mean} \pm \mathrm{SD})$ \\
\hline Benign (31) & $\mathbf{0 . 9 4}$ & $\mathbf{2 . 0 4}$ & $\mathbf{1 . 4 7} \pm \mathbf{0 . 2 8}$ \\
\hline Vascular (8) & 1.37 & 1.71 & $1.55 \pm 0.12$ \\
\hline Inflammatory (7) & 0.94 & 2.04 & $1.57 \pm 0.36$ \\
\hline $\begin{array}{l}\text { Optic nerve sheath } \\
\text { complex Neoplasm (7) }\end{array}$ & 0.98 & 1.73 & $1.35 \pm 0.25$ \\
\hline Infection (4) & 0.94 & 1.43 & $1.20 \pm 0.24$ \\
\hline $\begin{array}{l}\text { Peripheral nerve sheath } \\
\text { tumor (3) }\end{array}$ & 1.33 & 1.42 & $1.38 \pm 0.04$ \\
\hline $\begin{array}{l}\text { Lacrimal gland neoplasm } \\
\text { (1) }\end{array}$ & 1.78 & 1.78 & 1.78 \\
\hline Congenital (1) & 1.92 & 1.92 & 1.92 \\
\hline Malignant (13) & $\mathbf{0 . 6 3}$ & $\mathbf{1 . 2 5}$ & $\mathbf{0 . 9 4} \pm \mathbf{0 . 2 1}$ \\
\hline Metastases (6) & 0.97 & 1.25 & $1.14 \pm 0.11$ \\
\hline $\begin{array}{l}\text { Primary ocular malignancy } \\
\text { (3) }\end{array}$ & 0.71 & 0.83 & $0.77 \pm 0.06$ \\
\hline Lymphoproliferative (2) & 0.63 & 0.78 & $0.71 \pm 0.11$ \\
\hline Others (2) & 0.84 & 0.90 & $0.87+0.04$ \\
\hline
\end{tabular}

Abbreviation: ADC, apparent diffusion coefficient.

orbital abscess, and orbital cellulitis with subretinal abscess each. Peripheral nerve sheath tumors included two cases of schwannoma and a case of neurofibroma. Other benign lesions were a solitary fibrous tumor of the lacrimal gland and a dermoid. Choroid metastases (6) were the most common malignant lesion in our study followed by retinoblastoma (3). Other malignant lesions included a malignant optic glioma, an aggressive optic nerve sheath meningioma, and two lymphomas. In a similar study published by Soliman et al $(n=50)$, the descriptive analysis of benign and malignant lesions was not mentioned. ${ }^{25}$

From the diffusion-weighted images, we found that $52 \%$ of benign lesions appeared hypointense, while $42 \%$ appeared hyperintense and $6 \%$ appeared isointense. Among the malignant lesions, diffusion hyperintensity was seen in $46 \%$ cases, $46 \%$ were isointense, and $8 \%$ were hypointense. The distributions of DWI appearances of benign and malignant lesions were found to be significantly different from each other $(p=0.002)$.

In our study, mean ADC values for benign and malignant orbital lesions were found to be $1.47 \pm 0.28 \times 10^{-3}$ and 0.94 $\pm 0.2 \times 10^{-3} \mathrm{~mm}^{2} / \mathrm{s}$, respectively, suggesting a significant difference between them $(p<0.00001)$. This was in agreement with the results of Razek et al, Sepahdari et al, Fatima et al, Şerifoğlu et al, and Hemat who also reported that malignant lesions had much lower ADC values as compared with benign lesions. ${ }^{8,11,14,17,22}$ The malignant cases of optic nerve glioma and optic nerve sheath meningioma both displayed areas of diffusion restriction with lower ADC values as compared with the benign ones.

Also due to the small size of the choroid metastasis, some amount of partial volume averaging was present while measuring their ADC values. This is likely to result in falsely elevated $A D C$ values for choroid metastasis and hence broader distribution of ADC values for malignant lesions. Thus, the mean ADC value for malignant lesions was also calculated after excluding choroid metastasis and was found to be 0.78 $\pm 0.09 \times 10^{-3} \mathrm{~mm}^{2} / \mathrm{s}$. Sepahdari and Kapur et al also observed the effect of partial volume averaging on ADC values and concluded that ADC values for retinoblastoma had a strong inverse correlation with the size of the lesion. ${ }^{12}$

In our study, we observed a significant correlation of the age of the patient $(p=0.031)$ and the lesion size $(p=0.004)$ with respect to the risk of malignancy. However, this needs validation in a larger group due to the small sample size of our study.

In this study, ROC curve analysis identified $1.26 \times$ $10^{-3} \mathrm{~mm}^{2} / \mathrm{s}$ as the optimal ADC cut-off value for characterizing orbital masses with a sensitivity of $100 \%$, specificity of $80.65 \%$, and accuracy of $86.36 \%$. Hemat and Razek et al 
Table 5 Risk of orbital malignancy associated with different characteristics

\begin{tabular}{|c|c|c|c|c|c|c|c|}
\hline Characteristics & Categories & $\begin{array}{l}\text { Benign [No. } \\
(\%)]\end{array}$ & $\begin{array}{l}\text { Malignant } \\
{[\text { No. (\%)] }}\end{array}$ & $\begin{array}{l}\text { Odds } \\
\text { ratio }\end{array}$ & $\begin{array}{l}\text { Lower } \\
\text { limit }\end{array}$ & $\begin{array}{l}\text { Upper } \\
\text { limit }\end{array}$ & $p^{\mathrm{a}}$ \\
\hline \multirow[t]{4}{*}{ Age (y) } & $\leq 20(n=16)$ & $13(81.25)$ & $3(18.75)$ & 1.000 & & & \\
\hline & $21-40(n=12)$ & $11(91.66)$ & $1(8.33)$ & 0.436 & 0.014 & 4.381 & 0.435 \\
\hline & $41-60(n=10)$ & $4(40.00)$ & $6(60.00)$ & 5.841 & 1.020 & 42.476 & 0.031 \\
\hline & $61-80(n=6)$ & $3(50.00)$ & $3(50.00)$ & 3.959 & 0.476 & 36.541 & 0.413 \\
\hline \multirow[t]{2}{*}{ Gender } & Male $(n=15)$ & $10(66.67)$ & $5(33.33)$ & 1.000 & & & \\
\hline & Female $(n=29)$ & $21(72.41)$ & $8(27.59)$ & 0.763 & 0.193 & 3.178 & 0.692 \\
\hline \multirow[t]{3}{*}{ Lesion size } & $<10 \mathrm{~mm}(n=16)$ & $7(43.75)$ & $9(56.25)$ & 1.000 & & & \\
\hline & $11-15 \mathrm{~mm}(n=5)$ & $4(80.00)$ & $1(20.00)$ & 0.226 & 0.007 & 2.104 & 0.156 \\
\hline & $>15 \mathrm{~mm}(n=23)$ & 20 (86.95) & $3(13.05)$ & 0.128 & 0.022 & 0.574 & 0.004 \\
\hline
\end{tabular}

Note: Bold $p$-values indicate statistical significance.

* Obtained using Chi-square test.

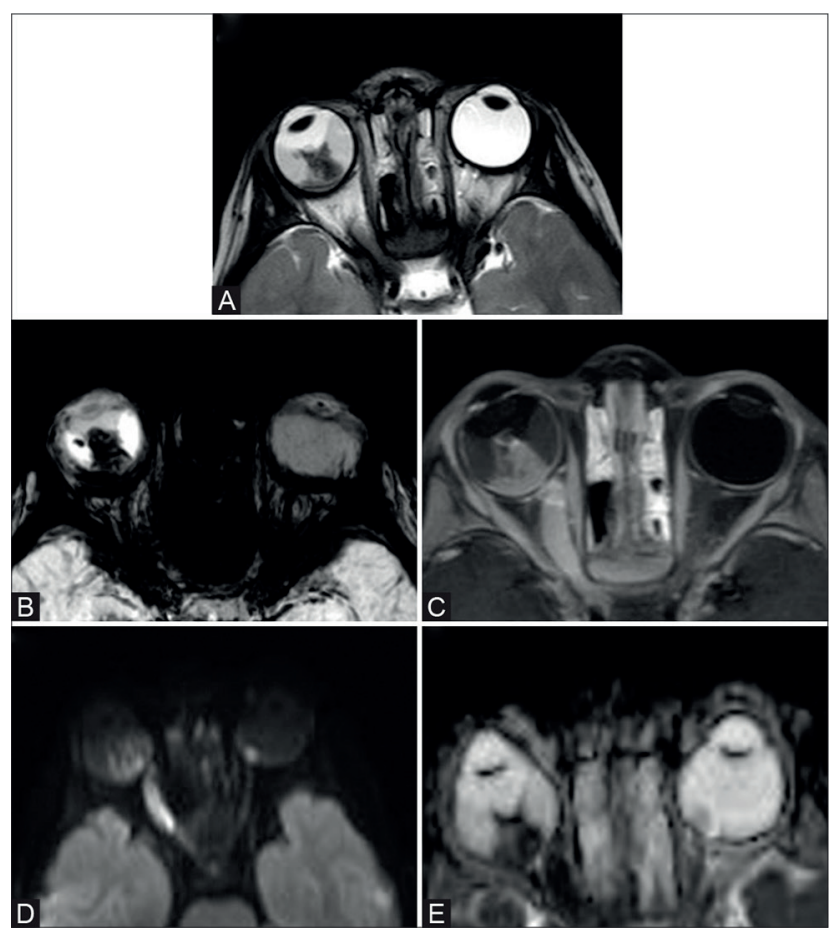

Fig. 1 (A-E) Retinoblastoma is seen as a hypointense right intraocular mass lesion on T2WI (A) with blooming on SWI (B). There is an extension to the right optic nerve reaching up to the orbital apex. The lesion shows avid heterogeneous enhancement on contrast-enhanced T1WI (C). DWI (D) and ADC maps (E) show diffusion restriction. ADC, apparent diffusion coefficient; DWI, diffusion-weighted imaging; SWI, susceptibility-weighted imaging; T1WI, T1-weighted imaging.

used ADC cut-off values of $0.93 \times 10^{-3}$ and $1.15 \times 10^{-3} \mathrm{~mm}^{2} / \mathrm{s}$ to differentiate between malignant and benign lesions with more than 80 and $90 \%$ accuracy, respectively. ${ }^{8,17}$ Sepahdari et al reported an ADC cut-off value of $1.0 \times 10^{-3} \mathrm{~mm}^{2} / \mathrm{s}$ with $84 \%$ specificity; however, a more stringent cut-off value of 0.9 $\times 10^{-3} \mathrm{~mm}^{2} / \mathrm{s}$ increased the specificity to $97 \%$ at the cost of reduced sensitivity. ${ }^{13}$ Fatima et al used a lower ADC threshold value of $0.84 \times 10^{-3} \mathrm{~mm}^{2} / \mathrm{s}$ to distinguish malignant lesions from benign lesions with more than $80 \%$ sensitivity and specificity. ${ }^{22}$ Roshdy et al did not calculate an optimal ADC

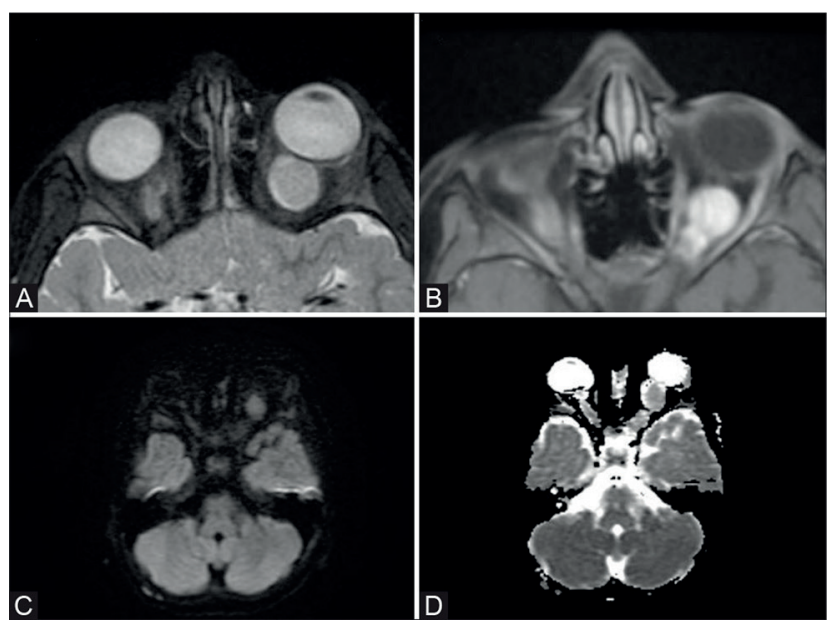

Fig. 2 (A-D) Optic nerve glioma is seen as a fusiform enlargement of the intraorbital segment of left optic nerve. It appears isointense on T2WI (A) with avid enhancement on contrast-enhanced T1W image (B). DWI (C) and ADC maps (D) demonstrate signal intensity similar to normal gray matter suggestive of benign lesion. ADC, apparent diffusion coefficient; DWI, diffusion-weighted imaging; T1WI, T1-weighted imaging.

cut-off value but observed an overlap between the ADC values of benign and malignant lesions. ${ }^{26}$ Soliman et al reported an ADC cut-off value of $0.9 \times 10^{-3} \mathrm{~mm}^{2} / \mathrm{s}$ with $76 \%$ sensitivity and $96 \%$ specificity. ${ }^{25}$

Of the 31 benign lesions in our study, four displayed ADC values lower than the threshold. Orbital abscess and orbital cellulitis with subretinal abscess demonstrated ADC values lower than the cut-off due to the presence of inflammatory cells. Other benign lesions to show falsely low ADC values were IgG4-related disease and optic nerve sheath meningioma. The lymphoplasmacytic infiltrates seen in IgG4-related disease and increased cellularity in meningioma could account for this. The mean ADC value of benign lesions after excluding the false-negative cases was $1.54 \pm 0.210^{-3} \mathrm{~mm}^{2} / \mathrm{s}$, which was higher than the overall mean $A D C$ of benign lesions $\left(1.47 \pm 0.28 \times 10^{-3} \mathrm{~mm}^{2} / \mathrm{s}\right)$. However, ADC values of all the malignant lesions were lower than the threshold. 

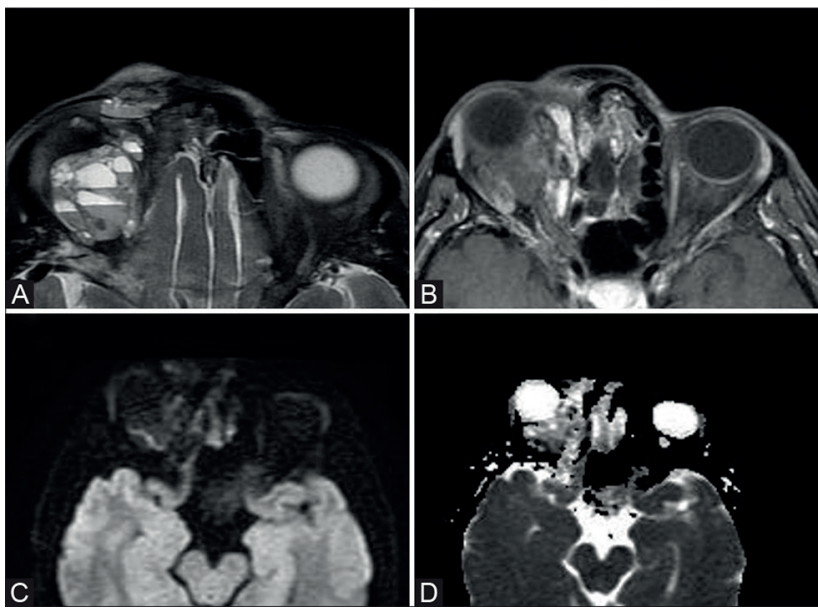

Fig. 3 (A-D) Lymphangioma is seen involving both intraconal and extraconal compartments of the right orbit with typical fluid-fluid levels on T2W (A) image. There is a mild patchy enhancement in the contrast-enhanced T1W image (B). DWI (C) and ADC maps (D) suggest the benign nature of the lesion. ADC, apparent diffusion coefficient; DWI, diffusion-weighted imaging; T1W, T1 weighted; T2W, T2-weighted imaging.
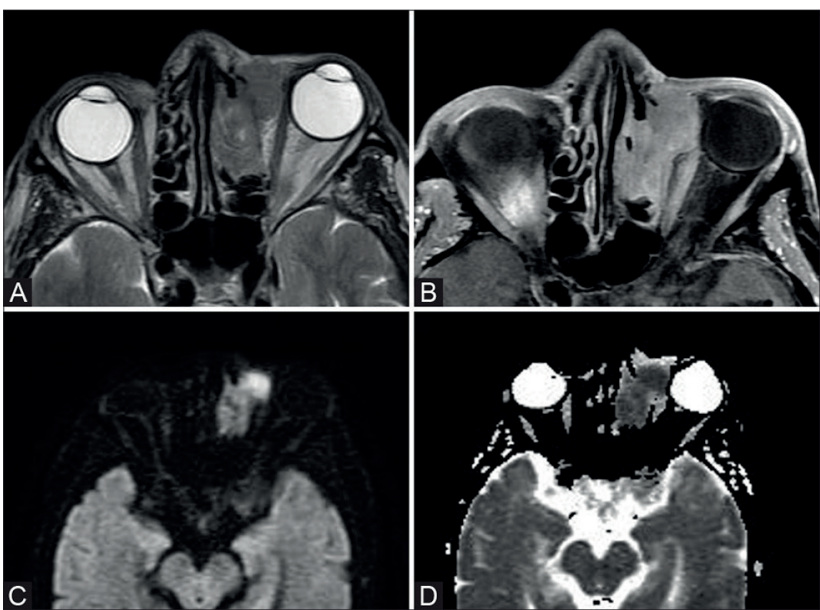

Fig. 4 (A-D) Lymphoma is seen as a mild T2 hypointense mass (A) involving the extraconal compartment of the left orbit with extension to the left ethmoid sinus. There is heterogeneous enhancement in the contrast-enhanced T1W image (B). DWI (C) and ADC maps (D) show restricted diffusion. ADC, apparent diffusion coefficient; DWI, diffusion-weighted imaging; T1W, T1 weighted.

Table 6 Descriptive statistics for different ADC threshold values $(n=44)$

\begin{tabular}{|l|l|l|l|l|l|}
\hline ADC threshold value $\left(\mathbf{1 0}^{-\mathbf{3}} \mathbf{m m}^{2} / \mathbf{s}\right)$ & Sensitivity (\%) & Specificity (\%) & PPV (\%) & NPV (\%) & Accuracy (\%) \\
\hline 1.04 & 69.20 & 90.00 & 75.00 & 87.50 & 84.09 \\
\hline 1.22 & 92.30 & 83.80 & 70.59 & 96.30 & 86.36 \\
\hline $1.26^{\text {a }}$ & 100.00 & 80.65 & 68.42 & 100.00 & 86.36 \\
\hline
\end{tabular}

Abbreviation: ADC, apparent diffusion coefficient; NPV, negative predictive value; PPV, positive predictive value.

aOptimal cut-off obtained using Youden's index.

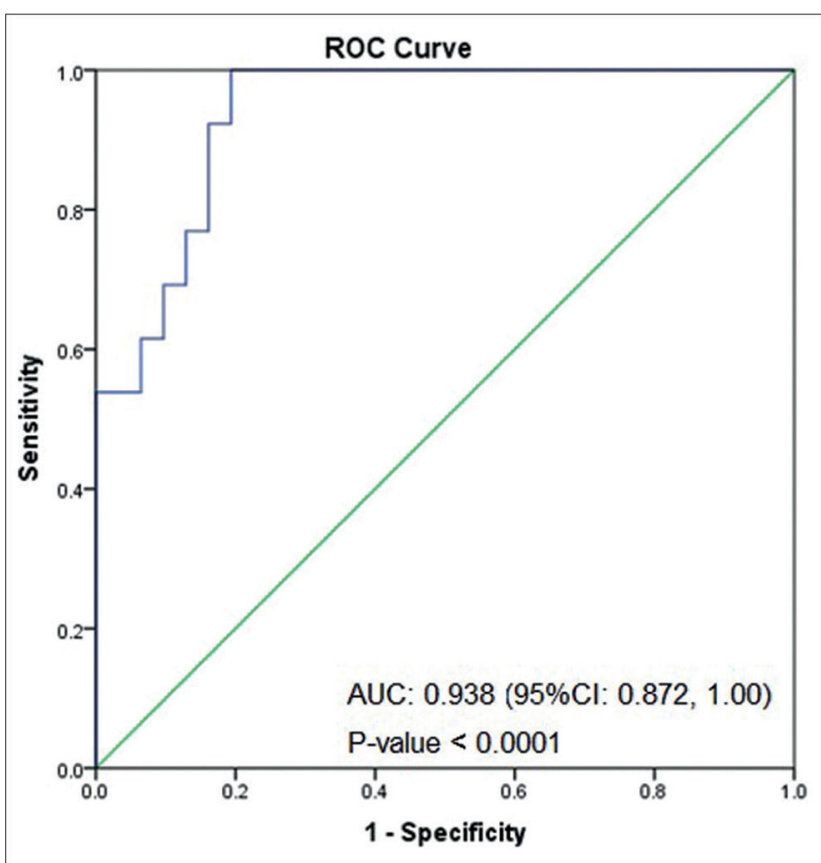

Fig. 5 Receiver operating characteristic curve analysis of ADC values to calculate an optimal ADC threshold to distinguish between benign and malignant orbital lesions. ADC, apparent diffusion coefficient.
Different ADC threshold values were used in previous studies and each one provided a different sensitivity, specificity, and accuracy. Therefore, a single ADC cut-off value cannot be considered sensitive and specific to distinguish between malignant and benign masses. Hence, we used a two-threshold model to characterize the orbital masses based on ADC values. Orbital masses were divided into three categories: likely malignant masses having $>90 \%$ probability of being malignant and an ADC value of less than 1.04 $\times 10^{-3} \mathrm{~mm}^{2} / \mathrm{s}$ ( $18 \%$ in our study); likely benign masses having $>90 \%$ probability of being benign and an ADC value of more than $1.22 \times 10^{-3} \mathrm{~mm}^{2} / \mathrm{s}$ ( $71 \%$ in our study); and indeterminate masses with an ADC value between 1.04 and 1.22 $\times 10^{-3} \mathrm{~mm}^{2} / \mathrm{s}$ ( $11 \%$ in our study). This two-threshold model for characterization of orbital mass lesions was also used by Sepahdari et al and Hemat. ${ }^{14,17}$

The limitation of this study includes partial volume averaging and susceptibility artifacts which were observed in choroid metastasis with the potential to impact the measured ADC values. The role of improved EPI and non-EPI DWI techniques should be explored to overcome this challenge. Another limitation of our study was the small sample size. Hence, we recommend prospective studies with a larger sample size to validate our results. 


\section{Conclusion}

We conclude that malignant orbital lesions have a significantly lower ADC value as compared with benign lesions. Two ADC thresholds were used to characterize most of the orbital masses with more than $90 \%$ confidence. Therefore, DWI with ADC is a quantitative, noninvasive tool adjunct to conventional MRI for the characterization of benign and malignant nature of the orbital masses.

\section{Financial Support and Sponsorship}

Nil.

\section{Conflicts of Interest}

There are no conflicts of interest.

\section{References}

1 Purohit BS, Vargas MI, Ailianou A, et al. Orbital tumours and tumour-like lesions: exploring the armamentarium of multiparametric imaging. Insights Imaging 2016;7(1):43-68

2 O'Neill M, Vega G, Cofnas P, Nagornaya N, Bhatia R. CT and MRI imaging spectrum of orbital masses: a pictorial essay and review of the literature. Cureus 2012;4:279

3 Mafee MF, Orbit: embryology, anatomy and pathology. In: Som PM, Curtin HD, eds. Head and Neck Imaging. 4th ed. St Louis, MI: Mosby; 2003 529-654

4 Aviv RI, Casselman J. Orbital imaging: part 1. Normal anatomy. Clin Radiol 2005;60(3):279-287

5 Goh PS, Gi MT, Charlton A. Tan C, Gangadhara Sundar JK, Amrith S. Review of orbital imaging. Eur J Radiol 2008;66(3):387-395

6 Dunarintu S, Birsasteanu F, Onet D, et al. Radio-imaging diagnosis of the ocular and orbital tumours. J Exp Med Surg Res 2008;15:5-12

7 Tailor TD, Gupta D, Dalley RW, Keene CD, Anzai Y. Orbital neoplasms in adults: clinical, radiologic, and pathologic review. Radiographics 2013;33(6):1739-1758

8 Razek AA, Elkhamary S, Mousa A. Differentiation between benign and malignant orbital tumors at 3-T diffusion MR-imaging. Neuroradiology 2011;53(7):517-522

9 Wang J, Takashima S, Takayama F, et al. Head and neck lesions: characterization with diffusion-weighted echo-planar MR imaging. Radiology 2001;220(3):621-630

10 Eida S, Sumi M, Sakihama N, Takahashi H, Nakamura T. Apparent diffusion coefficient mapping of salivary gland tumors: prediction of the benignancy and malignancy. AJNR Am J Neuroradiol 2007;28(1):116-121

11 Şerifoğlu İ, Oz İ̇, Damar M, Tokgöz Ö, Yazgan Ö, Erdem Z. Diffusion-weighted imaging in the head and neck region: usefulness of apparent diffusion coefficient values for characterization of lesions. Diagn Interv Radiol 2015;21(3):208-214
12 Kapur R, Sepahdari AR, Mafee MF, et al. MR imaging of orbital inflammatory syndrome, orbital cellulitis, and orbital lymphoid lesions: the role of diffusion-weighted imaging. AJNR Am J Neuroradiol 2009;30(1):64-70

13 Sepahdari AR, Kapur R, Aakalu VK, Villablanca JP, Mafee MF. Diffusion-weighted imaging of malignant ocular masses: initial results and directions for further study. AJNR Am J Neuroradiol 2012;33(2):314-319

14 Sepahdari AR, Politi LS, Aakalu VK, Kim HJ, Razek AA. Diffusion-weighted imaging of orbital masses: multi-institutional data support a 2-ADC threshold model to categorize lesions as benign, malignant, or indeterminate. AJNR Am J Neuroradiol 2014;35(1):170-175

15 Wang Y, Xiao LH. Orbital schwannomas: findings from magnetic resonance imaging in 62 cases. Eye (Lond) 2008;22(8):1034-1039

16 Xian J, Zhang Z, Wang Z, et al. Evaluation of MR imaging findings differentiating cavernous haemangiomas from schwannomas in the orbit. Eur Radiol 2010;20(9):2221-2228

17 Hemat EM. Characterization of orbital masses by diffusion-weighted magnetic resonance imaging (DWI) and apparent diffusion coefficient (ADC) value. Egypt J Radiol Nucl Med 2016;48:115-123

18 Politi LS, Forghani R, Godi C, et al. Ocular adnexal lymphoma: diffusion-weighted $\mathrm{mr}$ imaging for differential diagnosis and therapeutic monitoring. Radiology 2010;256(2):565-574

19 Sepahdari AR, Aakalu VK, Setabutr P, Shiehmorteza M, Naheedy JH, Mafee MF. Indeterminate orbital masses: restricted diffusion at MR imaging with echo-planar diffusion-weighted imaging predicts malignancy. Radiology 2010;256(2):554-564

20 Lope LA, Hutcheson KA, Khademian ZP. Magnetic resonance imaging in the analysis of pediatric orbital tumors: utility of diffusion-weighted imaging. J AAPOS 2010;14(3):257-262

21 Ragheb AS, Abd El-Rahman HM, Khattab HA. Can DWI \& ADC differentiate orbital lymphoma, non-specific orbital inflammation and orbital cellulitis? Egypt J Radiol Nucl Med 2012;43:157-164

22 Fatima Z, Ichikawa T, Ishigame K, et al. Orbital masses: the usefulness of diffusion-weighted imaging in lesion categorization. Clin Neuroradiol 2014;24(2):129-134

23 Shields JA, Shields CL, Scartozzi R. Survey of 1264 patients with orbital tumors and simulating lesions: the 2002 Montgomery Lecture, part 1. Ophthalmology 2004;111(5):997-1008

24 Ro SR, Asbach P, Siebert E, Bertelmann E, Hamm B, Erb-Eigner K. Characterization of orbital masses by multiparametric MRI. Eur J Radiol 2016;85(2):324-336

25 Soliman A, Aggag M, Abdelgawwad A, Aly W, Yossef A. Role of diffusion weighted MRI in evaluation of orbital lesions. Al-Azhar Int Med J 2020;1:331-336

26 Roshdy N, Shahin M, Kishk H, et al. MRI in diagnosis of orbital masses. Curr Eye Res 2010;35(11):986-991 